\title{
Retracted: Climatic, Regional Land-Use Intensity, Landscape, and Local Variables Predicting Best the Occurrence and Distribution of Bee Community Diversity in Various Farmland Habitats in Uganda
}

\author{
Psyche \\ Received 23 December 2013; Accepted 23 December 2013; Published 28 January 2014 \\ Copyright (C) 2014 Psyche. This is an open access article distributed under the Creative Commons Attribution License, which \\ permits unrestricted use, distribution, and reproduction in any medium, provided the original work is properly cited.
}

\begin{abstract}
The article titled "Climatic, Regional Land-Use Intensity, Landscape, and Local Variables Predicting Best the Occurrence and Distribution of Bee Community Diversity in Various Farmland Habitats in Uganda" [1], published in Psyche, has been retracted as it was found to include erroneous data. Its findings and conclusion cannot be relied on.
\end{abstract}

\section{References}

[1] T. Munyuli, "Climatic, regional land-use intensity, landscape, and local variables predicting best the occurrence and distribution of bee community diversity in various farmland habitats in Uganda," Psyche, vol. 2013, Article ID 564528, 38 pages, 2013. 